\title{
Nodes and networks in the governance of ecosystem-based adaptation: the case of the Bergrivier municipality, South Africa
}

\author{
Gina Ziervogel ${ }^{1,2}$ (D) Lorena Pasquini $^{3} \cdot$ Sarah Haiden $^{1,2}$
}

Received: 28 April 2016/Accepted: 11 June 2017 / Published online: 5 August 2017

(C) The Author(s) 2017. This article is an open access publication

\begin{abstract}
New forms of governance that foster multi-level and collaborative action have been identified as key to climate change adaptation. Ecosystem-based adaptation is emerging as an important type of adaptation response. Despite its recognized promise, it remains a challenging task to conceptualize governance regimes for it because of the involvement of numerous actors across the landscape scale. Both multi-level and collaborative forms of governance are required to involve relevant actors in decision-making and related actions. We explore the applicability of the theory of nodal governance, in conjunction with social network theory, to provide a framework for operationalizing the concepts of multi-level and collaborative governance. We use the Bergrivier municipal area of South Africa as a case study, focusing on organizations (nodes) that have the potential to implement ecosystem-based adaptation. We show that a nodal governance focus on institutional structures, mentalities, technologies, and resources can be highly effective for understanding the factors supporting or constraining ecosystem-based adaptation. A focus on the number and strength of network connections that actors share highlights how the numerous connections between organizations constitute an important opportunity for strengthening ecosystem-based adaptation outcomes in the future. The analysis suggests that in the Bergrivier municipal area, both agricultural best practices and restoration activities are side-lined compared to other activities (e.g., land use planning) despite the importance of the agricultural sector in the Bergrivier area. We argue that a nodal
\end{abstract}

Electronic supplementary material The online version of this article (doi:10.1007/s10584-017-2008-y) contains supplementary material, which is available to authorized users.

Gina Ziervogel

gina@csag.uct.ac.za

1 Department of Environmental and Geographical Science, University of Cape Town, Private Bag X3, Rondebosch 7701, South Africa

2 African Climate and Development Initiative, University of Cape Town, Private Bag X3, Rondebosch 7701, South Africa

3 Global Risk Governance Programme, Faculty of Law, University of Cape Town, Private Bag X3, Rondebosch 7701, South Africa 
governance focus, accompanied by the use of social network analysis, can be highly effective for understanding how to improve governance of adaptation at the local level.

\section{Introduction}

In recent years, there has been a growing interest in ecosystem-based adaptation (EbA), defined as the use of biodiversity and ecosystem services as part of an overall adaptation strategy to help people adapt to the adverse effects of climate change (e.g., Munang et al. 2013; Wamsler et al. 2014). The importance of EbA in the climate adaptation field is increasingly recognized, given the central role of natural resources and ecosystem services to support livelihoods and economies (Vignola et al. 2009). Promoted as a cost-effective, no-regret option offering multiple social, economic, and environmental co-benefits (e.g., Campos et al. 2014), EbA presents a range of opportunities for community-based initiatives and socio-economic development, the latter achieved through the generation of co-benefits such as food security, water purification, or the creation of "green jobs" (Roberts et al. 2012). Thus, an EbA approach can contribute to broader development goals and help to balance immediate development priorities with longer-term climate planning (Burch et al. 2014). In the context of EbA, natural resource governance regimes need to integrate climate risks and the inevitable ecological changes they bring into planning and implementation (Stein et al. 2013). However, the literature on the governance and mainstreaming of EbA is still in its infancy, though examples are beginning to appear (e.g., Pasquini and Cowling 2015; Wamsler et al. 2014).

Recent years have seen a growing interest in the governance of climate adaptation at the local government level (Measham et al. 2011; Pasquini et al. 2015; Bulkeley and Castan Broto 2013). Local governments, as the level of government closest to the ground, have a major role to play in the achievement of climate change adaptation. Local governments generally hold important powers in sectors relevant to the effective governance of EbA, such as spatial planning, water management, or disaster management (e.g., Bulkeley 2010; Pasquini et al. 2013). However, appropriate and effective EbA governance requires the involvement of numerous actors, as a landscape is seldom ever owned, used, or managed by a single stakeholder. Indeed, local governments may not own or manage the majority of land in their municipal areas (Pasquini and Cowling 2015). The policies and practices defined by one land owner, user, or manager may be limited in their scope if they ignore the policies and practices of others, or if others do not cooperate. Thus, creating partnerships between different actors within and beyond a local government's landscape is important to the governance of adaptation (Frohlich and Kneiling 2013).

A focus on the concepts of multi-level governance and collaborative governance as lenses for dealing with contemporary sustainability challenges broadly, and climate adaptation specifically, has emerged in recent decades (e.g., Termeer 2009; Sandström et al. 2015). Both these concepts are relevant to the governance of EbA, but both are multi-faceted and complex theoretical frameworks, and putting these concepts into use remains challenging. In this paper, we explore how nodal governance and social network theory can help to operationalize the concepts of multi-level and collaborative governance. We use the Bergrivier municipal area of the Western Cape, South Africa, as a case study to show how the theoretical concepts of nodal governance and social network theory can help to understand how people are considering, collaborating around, and putting into practice EbA responses. In so doing, we provide a deeper understanding of the applicability of nodal governance and social network theory frameworks to the governance of adaptation at the local level — the level at which climate change impacts are most immediately manifested. 


\section{Understanding nodal governance and networks as central to ecosystem-based adaptation}

A range of barriers have been found to constrain effective adaptation to climate change (Shackleton et al. 2015; Uittenbroek et al. 2013). Many barriers emerge as a result of the institutional arrangements or governance structures within the system of concern (Koch et al. 2007). For example, a frequently cited barrier to adaptation is a lack of collaborative or collective action between stakeholders (Biesbroek et al. 2009). In order to address these barriers, new forms of governance which promote collaboration and the expansion of social networks are required (Crona and Hubacek 2010).

Collaborative governance is a growing subject in the literature on climate change (Kinnear et al. 2013; Juhola and Westerhoff 2011). As defined by Emerson et al. (2012, p. 2), collaborative governance refers to "the processes and structures of decision making and management that engage people constructively across the boundaries of public agencies, levels of government, and/or the public, private, and civic spheres in order to carry out a public purpose that could not otherwise be accomplished." Such a form of governance provides opportunities to pool knowledge, understanding, expertise, and/or tangible resources (e.g., data, finances) to solve a common problem. Building on this, multi-level governance recognizes the importance of working across multiple scales, which is critical when managing whole landscapes (Armitage 2007), something that effective EbA requires. Yet, limited examples exist of multi-level governance for managing landscapes in the context of climate change (Juhola and Westerhoff 2011).

The relational dynamics between different actors, particularly the interaction of state and non-state actors, are an important feature of collaborative and multi-level governance. While potentially resource-intensive and time-inefficient, the deliberative nature of collaborative governance allows differences in opinions, interests, and recommendations to be considered. This deliberation helps to build trust and a shared understanding among stakeholders, creating opportunities for social learning and knowledge sharing (Pahl-Wostl 2009). Much empirical work remains, however, before it is fully understood how stakeholder relations and local governance structures influence the adaptation process (Crona and Hubacek 2010). In order to address this gap, this paper draws on the concept of nodal governance.

Nodes are points on a network, and the theory of nodal governance focuses attention on the internal characteristics of nodes, and how power is actually created and exercised within a social system. This focus on power is often lacking in climate change vulnerability and adaptation work (Ribot 2014). Power is a highly complex issue to study, and a comprehensive assessment of how power is created and conveyed in networks would require much more specific questions and methods than can be embraced within the context of our exploratory study (which seeks to illustrate more broadly how nodal governance and social network theory can be used to better understand collaborative governance). However, we start to engage with the question of power through understanding the nature of the nodes themselves; the reason for this is that while power is transmitted across networks, the actual point where knowledge and capacity are mobilized for transmission is the node (Burris et al. 2005).

Under the theory of nodal governance, nodes can be understood to exhibit four essential characteristics: mentalities, technologies, resources, and institutional structures (Burris et al. 2005). Mentalities refer to the node's way of thinking about the issue that needs to be governed, and are often informed by a very sector- or disciplinary-specific understanding of what the problem and solutions are. Technologies refer to the methods (e.g., policies, plans, tools) used 
by the node to exert influence over a particular course of events, and are usually a reflection of the node's mentalities. Resources are needed to support the operation of the node, and constitute the physical, financial, social, and human capitals that allow nodes to shape events in accordance with their mentalities and the technologies they employ. Lastly, a node must possess an institutional structure; i.e., it must have some institutional form. This need not be a formal or legal entity, but it must have sufficient stability and structure to enable the mobilization of resources, mentalities, and technologies over time. The focus on nodes seeks to emphasize that networks are dependent on the mentalities, technologies, institutional arrangements, and resources of nodes, and that nodes and nodal assemblages should be a major focus of analyses of governance (Burris 2004).

There has been a surprising lack of application of social network theory or social network analysis (SNA) in relation to nodal governance analyses. While nodal governance makes reference to mapping the ways in which nodes interact, for network position, number, and strength of connections, it has still not engaged with generating theoretical, conceptual, and empirical integration with social network theory - a field thus ripe for exploration. The primary focus of SNA is to understand patterns of relationships, which is particularly relevant for understanding complex governance arrangements in social-ecological systems - as the case of EbA exemplifies.

Although SNA has been used widely in natural resource management research, it has only recently started to be used in climate change adaptation research. SNA has been used to assess local adaptation processes, including how stakeholders participate in climate adaptation policy networks and how social networks can contribute to the governance of water resources in Australia (McAllister et al. 2014; Ingold et al. 2010; Kinnear et al. 2013). SNA has also been used to explore the legitimacy of urban adaptation in Helskinki (Klein et al. 2016) and to understand the importance of social capital in driving adaptation and transformation in the Australian agriculture sector (Dowd et al. 2014).

\section{Case study site and methods}

\subsection{The Bergrivier Municipality}

The Bergrivier Municipality (BM) is a local, rural municipality situated in the Western Cape Province, South Africa, with an area of ca. $4407 \mathrm{~km}^{2}$ and a population of 56,000 (BRM 2012). Commercial agriculture (particularly potato and rooibos tea farming), alien vegetation infestations, and extensive new housing developments are among the drivers of habitat transformation and biodiversity loss. Climate and impact models suggest that the increase in temperatures and decrease in winter rainfall predicted for could have far-reaching effects on the BM's terrestrial ecosystems, including reductions in water supply, sea level rise, species losses, and wildfire increases (Lötter et al. 2014). As the municipality's economy is driven by agriculture and a growing eco-tourism sector, there is concern that climate change will have severe impacts on local livelihoods, compounded by the municipality's low literacy levels (70.5\%) and the existence of very few alternative economic opportunities (BRM 2012).

\subsection{Data collection and analysis}

The BM was chosen as a case study because many of its economic and livelihood activities are directly reliant on ecosystem services, and are thus threatened by climate change impacts. In addition, there existed strong relationships between the municipality and researchers at the 
University of Cape Town (Ziervogel et al. 2016). Our research focused upon state and non-state organizations that have the potential to implement EbA within the BM area, based on their current engagement with conservation, restoration, and/or sustainable management activities relevant to the achievement of EbA in terrestrial ecosystems. These activities consisted of land use and development planning, landscape restoration, alien (invasive plants) clearing, integrated fire management, and sustainable farming practices. Although some of these activities may not explicitly address climate change impacts, all are directly and indirectly impacted by climate variability, and relevant to climate change adaptation. Hence, while the organizations under study might not have framed their plans and activities explicitly under an EbA tag, our research considered these activities as relevant to EbA, as outlined in the Supplementary Material.

Nine organizations were identified as central to the research. Face-to-face, semi-structured interviews with a middle or senior management representative from each organization (who worked within the BM area) were conducted during the period of October 2013-February 2014. Interview questions are shown in the Supplementary Material.

Data were transcribed and a nodal governance framework was used to structure our thematic analysis, exploring in a first step the institutional structures, mentalities, technologies, and resources of the organizations (nodes). To characterize the resources of the nodes, we employed SNA to examine the relational dynamics between nodes. SNA builds its explanations from examining patterns of social relations and exploring how these configurations influence both the behavior of individual nodes and that of the network as a whole. In this study, a basic sociogram (analytical diagram depicting patterns of social relations) was constructed and used to illustrate the channels through which information and/or resources flow from one node to another. Using a qualitative approach, questions regarding who the actors collaborate with, what form that collaboration takes, and the perceived strength of the dyadic ties between them (ranked on a scale of 1 to 3 ) informed the construction of a basic sociogram.

The second step of analysis took a holistic view of the existing nodes and networks to assess the limits, barriers, and enablers to EbA governance in the Bergrivier. Burris (2004) provides a useful approach to conducting such an assessment, which we drew upon in our analysis (see the Supplementary Material for the additional considerations that guided our analysis).

\section{Characterizing the nodes}

Table 1 presents a brief overview of the study's nine nodes, including their institutional structures and their engagement in a variety of EbA activities. In terms of key findings regarding the nodes' mentalities, all stakeholders interviewed presented a basic understanding of climate change, its anthropogenic causes, and its likely effects on the Western Cape and Bergrivier region specifically. Most $(n=7)$ felt certain that the impacts of climate change were already being experienced in the BM, and these concerns are borne out in the types of activities in which the organizations are engaged (Table 1) as well as the technologies they employ (Table 2). All respondents were familiar with the term "climate adaptation," although only two could define the specific term "ecosystem-based adaptation." All respondents, however, reported that they considered the activities they were undertaking as EbA-relevant activities (once the term had been explained to respondents who did not know it), in keeping with the idea that ecosystem conservation, restoration, and/or sustainable management activities are relevant to the achievement of climate change adaptation in terrestrial ecosystems. 
In addition, all stakeholders barring one (see below) felt that they had a responsibility to engage in adaptation. For instance, the local municipality cited Section 152(1) of the Constitution which states that "the objects of local government are to promote a safe and healthy environment," accepting this as reason enough to "take climate adaptation on as [their] responsibility" (despite there being no requirement in South African law for public entities to undertake climate adaptation specifically). In the municipal case, this finding is extremely interesting, given its lack of resemblance to the findings of other studies, both international (Burch 2010; Measham et al. 2011) and local (e.g., Pasquini et al. 2013; but see Ziervogel and Parnell 2014 for an exception). Such studies have highlighted how, in the absence of explicit mandates for adaptation, some municipalities have claimed either to be unable or unwilling to engage in adaptation owing to their already crowded agendas. Only SAKO, one of the organisations interviewed, did not view climate change as an immediate threat; the organization reported not having witnessed any changes that could be directly linked to climate change, and did not feel it had a responsibility to engage in adaptation.

The following section focuses on two important suites of technologies used by the different organizations: legislation and policies, and maps (Table 2). The assumption that technologies reflect mentalities would appear to be confirmed by the nodes' use of legislation and policy. All nodes reported relying upon national and provincial legislation for governing natural resources in light of climate change (Table 2). These pieces of legislation guide the identification of priority actions for ensuring the protection of the environment, as well as people and communities, from various hazards and risks. As stated above, there is currently no legislation with explicit mention of climate change in South Africa. It might not be surprising to find environmentally based organizations taking it upon themselves to extend environmental legislation to include climate change among their responsibilities. However, it is more surprising that municipalities and agricultural organizations might do so, and go as far as explicitly including it in their local-level policies.

The majority of stakeholders viewed fine-scale Critical Biodiversity Area (CBA) maps as essential planning tools (Table 2). These maps are produced by the Fine-scale Biodiversity Planning Project led by CapeNature and the South African National Biodiversity Institute. They are key to determining priority areas for alien clearing and landscape restoration, as well as identifying suitable parcels of land to be incorporated into landscape corridors for climate-induced species migration (Pence 2008). Moreover, they are of great use to decision-making procedures related to the granting/denying of approval of land use applications, a key municipal function (Pence 2008). CapeNature is currently reviewing and updating the maps with new information that has emerged from the climate science fraternity. This new information enables the creation of an EbA layer, incorporating areas with climate refugia (e.g., south facing slopes and gorges), and environmental gradients (e.g., topographic, temperature, and precipitation) to allow species migration. Despite the fact that these maps have been made available to the general public, ${ }^{1}$ and that GIS technology has become substantially cheaper and easier to use over the years (e.g., Grimshaw 2000), SAKO claimed that not knowing how to access these maps had constrained the organization's ability to make ecologically sensitive planning decisions. All of the other organizations accessed and used the CBA maps or, in the case of the two organizations most concerned with preventing and suppressing unwanted wildfires, other types of maps (Table 2).

In terms of resources, all respondents unsurprisingly reported being limited by financial constraints. Current EbA activities are financed either by mainstreaming adaptation into

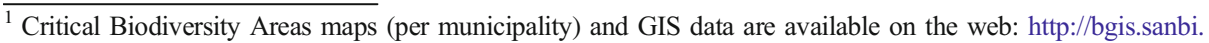
org/fsp/project.asp
} 
Table 1 Description of nodes, including their institutional structures, and their activities related to ecosystembased adaptation (terrestrial systems only)

\begin{tabular}{|c|c|c|}
\hline Node & Description & Current/planned EbA activities \\
\hline $\begin{array}{l}\text { Bergrivier Municipality } \\
\text { (BM) }\end{array}$ & $\begin{array}{l}\text { Local municipality responsible for local } \\
\text { government in the Bergrivier } \\
\text { municipal area (Fig. 1) }\end{array}$ & $\begin{array}{l}\text { - Removal of alien invasive plants } \\
\text { - Establishment of an adaptation forum } \\
\text { for the agricultural sector specifically } \\
\text { - Protection of major landscape corridors } \\
\text { from biodiversity-incompatible devel- } \\
\text { opment } \\
\text { - Mainstreaming of adaptation into } \\
\text { municipal governance via capacity } \\
\text { building of officials, sector } \\
\text { stakeholders, and community }\end{array}$ \\
\hline $\begin{array}{l}\text { West Coast District } \\
\text { Municipality (WCDM) }\end{array}$ & $\begin{array}{l}\text { District municipality comprised of five } \\
\text { local municipalities, including the } \\
\text { BM. (District municipalities are made } \\
\text { up of a number of local municipalities } \\
\text { that fall in one district, usually } \\
\text { between four to six. The district } \\
\text { municipality has to co-ordinate devel- } \\
\text { opment and delivery in the whole } \\
\text { district. District- and local-level mu- }\end{array}$ & $\begin{array}{l}\text { - Removal of alien invasive plants } \\
\text { (particularly around the lower Berg) } \\
\text { - Coordination of fire management (from } \\
\text { the WCDM Disaster Management } \\
\text { Centre) } \\
\text { - Rehabilitation of landscapes } \\
\text { - Provision of trees (200 trees to each } \\
\text { local municipality in 2013) and } \\
\text { planting support }\end{array}$ \\
\hline
\end{tabular}
nicipalities share the responsibility for local government within their jurisdictions)

Cape Nature (Porterville A parastatal with the statutory Office) responsibility for biodiversity conservation in the Western Cape

- Removal of alien invasive plants

- Promotion of stewardship of private land through the establishment of biodiversity corridors (e.g., the Groot Winterhoek and Sandveld Corridors)

- Provision of environmentally sensitive advice on development applications

LandCare

A government-funded sustainable land

- Coordination of fire management

- Removal of alien invasive plants management program, established un- • Rehabilitation of landscapes der the National Department of Agri- - Promotion of soil conservation and culture

Working on Fire (WoF) A national Expanded Public Works Programme (a government initiative to alleviate poverty and unemployment in South Africa). The focus of $\mathrm{WoF}$ is on wildfire prevention, management, and suppression

Greater Cedarberg Fire Protection Association (GCFPA)

A local association established in terms of the Veld and Forest Fire Act 101 of 1998 as a means to involve local government and landowners in Integrated Fire Management sustainable farming techniques

- Provision of planning, technical, and operational (on-the-ground) support to existing wildfire fighting services

- Awareness campaigns related to fire risk and prevention

- Development and application of an integrated wildfire management strategy

- Awareness campaigns related to fire risk and prevention

- Augmentation of membership base (landowners and their staff) and training of members with regards to fire-fighting

- Management and prevention of wildfires

Sandveld Potato Growers A local association acting on behalf of Association (SAKO) most potato producers in the Sandveld (i.e., the area between the Cederberg Mountains and the sea, bounded by

- Promotion of sustainable potato farming practices through the implementation of the biodiversity best practice guidelines 
Table 1 (continued)

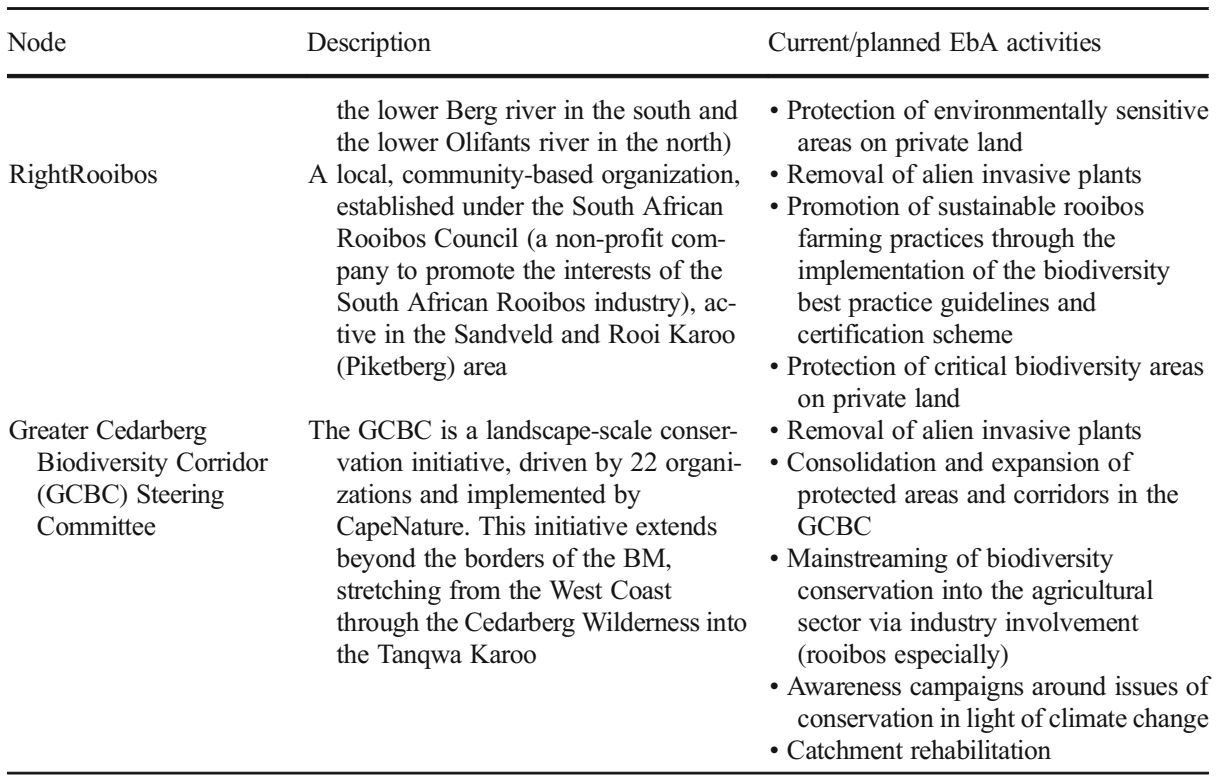

existing projects and programs (as occurs in the municipalities) or via donor funding (as happens for example within CapeNature and the GCBC). More interesting is the issue of the availability of human and social capital to organizations, in relation to network connections. Nodal conceptions of governance focus attention on the way in which resources are brought to bear via the linkages established between nodes. For instance, no organization in the case study had adequate in-house scientific resources (personnel and material) in the field of climate change and EbA. Instead, organizations were reliant on their networks, and various partnerships with local universities and research institutes, for such information. Rather than a weakness, several organizations $(n=5)$ explicitly mentioned this as a strength. These networks provide an opportunity to involve a range of actors, each able to offer a different but useful perspective. These views are exemplified in the following statement by a CapeNature respondent.

"If I could choose, I would put more energy into developing the network with external partners than developing that capacity within our own scientific services. The network throws a wider web [...] It adds a different perspective, and it's usually broader with people with different disciplines as well, so it's not just the climate scientists, it's people from a social perspective, environmental law perspective, or whatever, plus local practitioners ... and I think that's quite essential when you really want something to work."

\section{Social network analysis}

Because the availability of or access to resources is often the consequence of nodal linkages, we built a sociogram to visualize the overall structure of the network of actors involved in EbA in our case study area (Fig. 1). As can be seen through the sociogram, varying levels and numbers of connections exist between the nodes. 
Table 2 Summary of key technologies, in terms of legislation/policies and maps (other less critical technologies are not listed here), used by the nodes to plan/implement EbA activities in the Bergrivier municipal area

\begin{tabular}{|c|c|c|}
\hline Node & Legislation and policies & Maps \\
\hline $\mathrm{BM}$ & $\begin{array}{l}\text { - Municipal Systems Act, } 2000 \\
\text { - SA Constitution, Schedule 4B and 5B } \\
\text { - BM Integrated Development Plan } \\
\text { - BM Spatial Development Plan }\end{array}$ & $\begin{array}{l}\text { - Fine-scale maps (i.e., Critical } \\
\text { Biodiversity Area Maps) }\end{array}$ \\
\hline WCDM & $\begin{array}{l}\text { - Municipal Systems Act, } 2000 \\
\text { - SA Constitution, Schedule 4B and 5B } \\
\text { - District Integrated Development Plan } \\
\text { - District Spatial Development Plan }\end{array}$ & - Fine-scale maps \\
\hline Cape Nature & $\begin{array}{l}\text { - National Environmental Management } \\
\text { Act, } 107 \text { of } 1998 \\
\text { - Provincial Nature Conservation } \\
\text { Ordinance } 19 \text { of } 1974\end{array}$ & - Fine-scale maps \\
\hline LandCare & $\begin{array}{l}\text { - Conservation of Agricultural Resources } \\
\text { Act, } 43 \text { of } 1983\end{array}$ & - Fine-scale maps \\
\hline GCBC Steering Committee & $\begin{array}{l}\text { - National Environmental Management } \\
\text { Act, } 107 \text { of } 1998\end{array}$ & - Fine-scale maps \\
\hline RightRooibos & $\begin{array}{l}\text { - National Environmental Management } \\
\text { Act, } 107 \text { of } 1998\end{array}$ & - Fine-scale maps \\
\hline WoF & $\begin{array}{l}\text { - National Veld and Forest Fire Act, } \\
101 \text { of } 199\end{array}$ & $\begin{array}{l}\text { - Fire risk detection maps (created } \\
\text { using Fire Danger Indices and } \\
\text { satellite-based Advanced Fire } \\
\text { Information Systems) }\end{array}$ \\
\hline GCFPA & $\begin{array}{l}\text { - National Veld and Forest Fire Act, } \\
101 \text { of } 1998\end{array}$ & - Fire risk detection maps \\
\hline SAKO & $\begin{array}{l}\text { - National Environmental Management } \\
\text { Act, } 107 \text { of } 1998\end{array}$ & \\
\hline
\end{tabular}

Among the central nodes (viz. LandCare, CapeNature, and the local and district municipalities), strong ties have developed owing largely to ongoing deliberation over land use and spatial development planning (Fig. 1). This suggests that the technologies of legislation and policy could help to convene actors; the Cape Land Use Planning Ordinance (LUPO) of 1985 affords local municipalities the authority to approve or refuse land use applications, and the BM has acknowledged the need to consult other interested and affected parties prior to making its decisions, in recognition of the fact that a landscape is seldom ever owned, used, or managed by a single stakeholder. It is further in the interests of CapeNature and LandCare to collaborate with the municipality to ensure that the most ecologically sensitive planning decisions are made and that they support each other's work. Thus, a shared, recognized mandate can act as an enabler to collaboration. Another EbA-relevant activity around which numerous actors converged consists of the removal of alien invasive plants (Table 1 and Fig. 1). In the South African context, this is not a surprising finding, as discussed by Pasquini and Cowling (2015) who explore the "popularity" and history of this action.

Several respondents $(n=7)$ made reference to the importance of forums for fostering interorganizational linkages. The majority of respondents reported having the opportunity to interact with other stakeholders within the meetings of the GCBC Steering Committee, a multi-sectoral group of representatives stemming from 22 organizations, including local and district municipalities, government departments, communities, NGOs, and conservation agencies. The role of the Steering Committee is to oversee, advise, and facilitate the implementation of the GCBC, a landscape-scale initiative which extends beyond the borders of the BM area. 


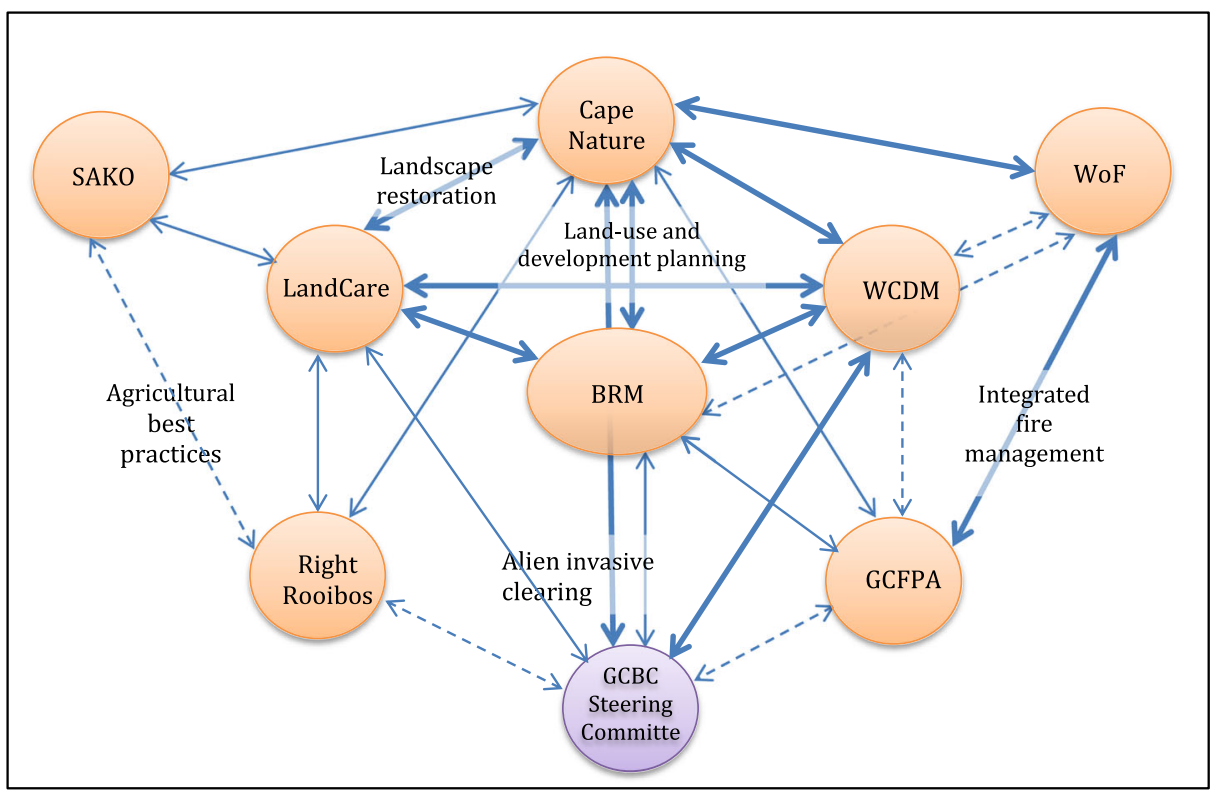

Fig. 1 Interactions between nine nodes involved in the management of terrestrial ecosystems in the Bergrivier municipal area (the sociogram does not map the links to actors who are not directly involved in EbA activities in the Bergrivier, such as universities). The thickness of each line indicates the strength of the dyadic ties between nodes, as perceived by the nodes themselves (thick solid line $=$ strong, thin solid line $=$ moderate, dotted line = weak; the length of each line is of no consequence). EbA activities with which nodes are most commonly associated are located nearest those nodes most active in those activities. The GCBC Steering Committee is highlighted in purple to reflect its nature as a "super-structural" node

Such a forum is critical for encouraging organizations to collaborate across their respective jurisdictions so that they might make an impact at the landscape scale. We thus view the GCBC Steering Committee as a "super-structural" node, which, following Drahos (2004, p. 405), we define as a "structure that brings together actors who represent networks in order to concentrate resources and technologies for the purpose of achieving a common goal."

Investigations revealed that the GCBC Steering Committee is one of the most connected and influential nodes in the Bergrivier region (Fig. 1). Indeed, the implementation of several large-scale EbA-related projects (e.g., the expansion of corridors, catchment rehabilitation; see Table 1) is attributable to the GCBC. This underscores the important role that supra-structural nodes can play. However, it is evident from the sociogram that there exists significant opportunity to strengthen the GCBC Steering Committee's linkages to other actors in the $\mathrm{BM}$ area further. Finally, the sociogram reveals that the two least-connected nodes in the network consist of SAKO and RightRooibos, shown as outliers in Fig. 1. These two nodes represent the agricultural sector, and their marginalization holds particular implications for the governance of natural resources in the Bergrivier landscape, as discussed below.

\section{Assessment of governance nodes and networks}

The application of a nodal governance framework has provided a valuable tool for identifying factors that support or constrain EbA within the BM landscape, providing lessons that are 
potentially transferable beyond this landscape's borders. The nodes' mentalities suggest a governance landscape that is very amenable to taking up the adaptation challenge. Below, we discuss some of factors that are likely to contribute to such amenability.

The lack of funds and "in-house" human resources (a common barrier to adaptation; e.g., Ziervogel and Parnell 2014; Moser and Ekstrom 2010; Roberts et al. 2012) seems to have led the study organizations to focus on building links to other organizations. Such links can drive cooperation, an important precursor to collaborative governance. Collaborative environmental governance is particularly important for achieving EbA (Vignola et al. 2013), as several organizations at the landscape level need to work together to overcome the institutional and legislative fragmentation of landscapes. The presence of linkages can also enable information exchange, which is critical for effective ecosystem governance across administrative scales and boundaries (Vignola et al. 2013).

Thus, the apparent amenability of the study nodes to implement EbA might also be explained by the numerous connections formed between them; opportunities for collaboration and convening are present in many instances, and building on these existing collaborations is an important way forward for strengthening EbA in the future. Burris (2006, p. 206), in discussing nodal governance in the context of health and security, notes that "access to individual and social resources is the key to better outcomes," and the availability of, or access to, resources is often the consequence of nodal linkages. Our study suggests that by understanding the nodes and networks better, EbA governance outcomes could be improved through better access to knowledge, mobilizing more available resources and strengthening the relationships of critical nodes to others, as outlined in more detail below.

However, the opportunity to strengthen ties as well as form new relations between our study's nodes still exists. A tool such as the sociogram proves highly useful in identifying where such social network opportunities might lie. The sociogram makes clear that particularly, SAKO could be more extensively linked to other nodes in the network. The relative isolation of SAKO may explain, in part, its particularly different mentalities regarding climate change and adaptation as compared to the other nodes, and its lack of use of a technology common to all other organizations (maps). Had SAKO been better connected, it might have been better able to access the knowledge and expertise in natural resource management held by the other nodes, and, as the section below explicates, it might have held greater power in the Bergrivier governance landscape.

A sociogram is a highly useful tool for revealing the outcomes of EbA governance on the ground. Nodes able to mobilize greater resources can dominate a governance landscape; hence, those located at points of high intersectionality, and thus having greater connective resources, could dominate (Burris 2004). In other words, they could possess greater power. It is immediately apparent from the sociogram that both agricultural best practices and restoration activities are implemented by fewer organizations than other activities. These sustainable agricultural practices are possibly being side-lined because the focus of the more "powerful" (i.e., more connected, in our case) nodes, within the current governance landscape, are on land use planning and alien invasive vegetation issues (though this is unlikely a deliberate decision).

Agriculture, however, is the most important economic driver in the BM. Further, agricultural nodes have the capacity to alter large portions of the landscape. The sustainability of this sector is therefore likely to be important to economic and environmental sustainability of the $\mathrm{BM}$ as a whole. As a further step, it should be possible to rank the relative "importance" of 
different EbA activities to the sustainable development of an area, and through the sociogram - a relatively quick, easy, and cheap tool - assess how this prioritization fares against what is actually happening on the ground. From a nodal governance perspective, the creation of a new node or strengthening the power of an existing node (for e.g., through increasing network connections) not only fills a gap in governance but also has the potential to shift a suboptimal community governance system in ways that lead to more efficacy (Burris 2006, p. 211).

A nodal governance analysis with an accompanying SNA can also suggest where to direct further resources, for example, where to target extension services. It can suggest where technologies may require modification for optimal governance outcomes. The sociogram made explicit how the majority of interactions between stakeholders occur over land use and development planning. These functions are most often regulated by the Land Use Planning Ordinance No. 15 of 1985, the spatial planning and land use management legislation which stakeholders are most comfortable with, in a highly confusing spatial and land use planning regulatory framework in South Africa (SACN 2012). What is noteworthy is that none of the organizations interviewed perceived this legislation as being a technology employed for natural resource management (Table 2). Although the National Environmental Management Act 107 of 1998 was established specifically to "provide for cooperative environmental governance," it does not appear to be directly linked to the majority of cooperation occurring in the BM.

Part of the reason for the majority of collaborations being established over land use and development planning may lie in the widespread use that stakeholders in the BM make of the CBA maps - which is an acknowledged technology. As we noted earlier, CBA maps are critical to decision-making procedures related to the granting/denying of approval of land use applications, a key municipal function (Pence 2008). These maps are also, from another perspective, a resource, and their availability may be contributing to the particular nature of the BM landscape. We noted earlier that technologies, mentalities, and resources are not cutand-dried categories. It is possible that the availability of maps may even be contributing to the particular mentalities of the BM governance landscape. As Johnston and Shearing (2003, p. 29) note in the context of the governance of security, while the modes and processes of governance influence the tools that are chosen, the reverse may sometimes be true; the technologies available or chosen may shape the mentalities of an institution. It is interesting in this context to note that SAKO is both the only organization that does not make use of the CBA maps, and the only organization to have a widely different mentality as compared to the other nodes. It is therefore possible that a process of co-creation is at play, whereby the availability of fine-scale maps contributed to changing mentalities, and the use of maps is not simply a reflection of the nodes' mentalities.

More generally, we expect that mentalities, technologies, and resources will interplay and exert reciprocal effects on each other. Particularly, network connections can spread mentalities, knowledge, (other) resources, and technologies in the Bergrivier area. For instance, relatively strong and dense network connections in the BM area are likely to be affecting the mentalities of the nodes, leading to convergence among them; the interaction, in terms of frequency and richness, between members of a social network enhances learning and change in norms. Network connections also promote the exchange of knowledge between nodes, improving governance outcomes (Dowd et al. 2014). Pasquini and Cowling (2015) and Pasquini et al. (2015) found that municipalities with links to "knowledge bases" outperformed municipalities without such connections on adaptation and EbA issues. 
The combined use of SNA and nodal governance offers an explanation for how a group of actors can overcome the "lock in" effects of existing legislative, regulatory, and organizational practices, which elsewhere appear to be inhibiting municipal areas from achieving EbA or other forms of effective environmentally related governance (e.g., Pasquini et al. 2013; Wamsler et al. 2014).

\section{Conclusion}

Our case study leads us to draw a number of conclusions about the application of nodal governance to the adaptation field. A theory of nodal governance provides a highly detailed account of the process through which EbA in the Bergrivier municipality is governed. An important aspect of the nodal approach is that it sees "governance as a relationship contained within a shifting network of alliances rather than as a product of the realization of governing interests" (Johnston 2006, p. 34). The focus of EbA governance in the Bergrivier reflects the particular relationships actualized in the study area, and not only the nodes' mentalities. Thus, activities such as alien invasive clearing or land use planning are more prevalent than activities such as sustainable agricultural practices. This leads us to ask whether the "optimal" configuration for EbA within the Bergrivier landscape is being achieved. Given that agriculture is the principal income generator for the municipal area, it is possible to conclude that a governance deficit exists.

The use of nodal governance and SNA allows for the characterization and visualization of nodes and their networks, and explains their impact on governance outcomes including knowledge access, mobilization of resources, and critical relations to others. It also allows for the analysis of how power is created and exercised within a governance system (though, given the exploratory nature of our study, our treatment of power issues here is necessarily superficial and thus for illustrative purposes; future research comprehensively analyzing power issues with nodal governance and SNA would be critically useful). As such, these theories and concepts can guide the design of interventions to respond to determined governance deficits. In our case study, interventions could focus upon facilitating an increase in nodal arrangements between SAKO and RightRooibos and the other local nodes as well as recognizing the importance that maps play as a technology in the region. Thus, nodal and network conceptions of governance can be extremely useful approaches for finding more innovative institutional arrangements to improve the delivery of social goods.

This paper makes an important theoretical contribution by demonstrating the potential value of nodal governance theory and social network theory to both theory and practice regarding the governance of adaptation. To our knowledge, this paper is the first to apply a nodal governance approach to climate adaptation, and among one of the first to apply SNA to the adaptation domain. Notwithstanding our contribution, a far greater conceptualization of the interplay between nodal governance and SNA is necessary. For example, possible questions for future research to address include the following: do nodes make use of other nodes to promote their values and interests? Who has access to nodes, and how? How is governing "power" distributed between different types of nodes, e.g., state and non-state nodes, and why? Such questions provide an indication of the rich empirical and theoretical possibilities that could start to provide guidance on how to strengthen the complex governance response needed in the context of climate change and natural resource management. 
Acknowledgements All the respondents who gave up time to be interviewed are gratefully acknowledged. The authors thank the anonymous reviewers for their valuable comments. This work is based upon research supported by the African Climate and Development Initiative and by the National Research Foundation of South Africa, under the Fulcrum Institutions for Socio-Ecological Resilience project of the Global Change, Society and Sustainability research programme. The authors acknowledge that opinions, findings, and conclusions or recommendations expressed in this publication are that of the authors, and that the National Research Foundation accepts no liability whatsoever in this regard.

Open Access This article is distributed under the terms of the Creative Commons Attribution 4.0 International License (http://creativecommons.org/licenses/by/4.0/), which permits unrestricted use, distribution, and reproduction in any medium, provided you give appropriate credit to the original author(s) and the source, provide a link to the Creative Commons license, and indicate if changes were made.

\section{References}

Armitage D (2007) Governance and the commons in a multi-level world. Int J Commons 2(1):7-32

Biesbroek GR et al. (2009) Institutional governance barriers for the development and implementation of climate adaptation strategies, Working paper for the International Human Dimensions Programme (IHDP) conference "Earth System Governance: People, Places, and the Planet", December 2-4, Amsterdam, the Netherlands.

BRM (2012) Integrated Development Plan 2012/13-2016/17

Bulkeley H (2010) Cities and the governing of climate change. Annu Rev Environ Resour 35(1):229-253

Bulkeley H, Castan Broto V (2013) Government by experiment? Global cities and the governing of climate change. Trans Inst Br Geogr 38(3):361-375

Burch S (2010) In pursuit of resilient, low carbon communities: an examination of barriers to action in three Canadian cities. Energy Policy 38(12):7575-7585. Available at:. doi:10.1016/j.enpol.2009.06.070

Burch S et al (2014) Triggering transformative change: a development path approach to climate change response in communities. Clim Pol 14(4):467-487

Burris S (2004) Governance, microgovernance and health. Temple Law Review 77:335-361

Burris S (2006) From security to health. In: Wood J. \& Dupont B (eds) Democracy, society and the governance of security. New York, USA: Cambridge University Press, pp 196-216

Burris S, Drahos P, Shearing C (2005) Nodal governance. Australian Journal of Legal Philosophy 30:30-58

Campos M, Velázquez A, McCall M (2014) Adaptation strategies to climatic variability: a case study of smallscale farmers in rural Mexico. Land Use Policy 38:533-540 Available at: http://www.sciencedirect. com/science/article/pii/S0264837713002780

Crona B, Hubacek K (2010) The right connections: how do social networks lubricate the machinery of natural resource governance? Ecol Soc 15(4):18

Dowd A-M et al (2014) The role of networks in transforming Australian agriculture. Nat Clim Chang 4(7):558-563

Drahos P (2004) Intellectual property and pharmaceutical markets: a nodal governance approach. Temple Law Rev 77:401-424

Emerson K, Nabatchi T, Balogh S (2012) An integrative framework for collaborative governance. J Public Admin Res Theory 22(1):1-29. Available at: http://jpart.oxfordjournals.org/content/early/2011/05/02/jopart.mur011.abstract

Frohlich J, Kneiling J (2013) Conceptualising climate change governance. In: Frohlich J, Filho W (eds) Climate change governance. Springer, Berlin, pp 9-26

Grimshaw DJ (2000) Bringing geographical information systems into business. Wiley: New York, pp 362. Available at: https://books.google.com/books?hl=en\&lr=\&id=xQby7pJC6KwC\&pgis=1

Ingold K, Balsiger J, Hirschi C (2010) Climate change in mountain regions: how local communities adapt to extreme events. Local Environ 15(7):651-661

Johnston L (2006) Transnational security governance. In: Wood J, Dupont B (eds) Democracy, society and the governance of security. New York, USA: Cambridge University Press, pp 33-51

Johnston L, Shearing C (2003) Governing security: Explorations in policing and justice. Abingdon: Routledge.

Juhola S, Westerhoff L (2011) Challenges of adaptation to climate change across multiple scales: a case study of network governance in two European countries. Environ Sci Pol 14:239-247

Kinnear S et al (2013) Network governance and climate change adaptation: collaborative responses to the Queensland floods. National Climate Change Adaptation Research Facility, Gold Coast

Klein J, Mäntysalo R, Juhola S (2016) Legitimacy of urban climate change adaptation: a case in Helsinki. Reg Environ Chang 16(3):815-826

Koch IC, Vogel C, Patel Z (2007) Institutional dynamics and climate change adaptation in South Africa. Mitig Adapt Strateg Glob Chang 12(8):1323-1339 
Lötter D, le Maitre D (2014) Modelling the distribution of Aspalathus linearis (Rooibos tea): Implications of climate change for livelihoods dependent on both cultivation and harvesting from the wild. Ecol Evol 4(8): 1209-1221

McAllister RRJ, McCrea R, Lubell MN (2014) Policy networks, stakeholder interactions and climate adaptation in the region of South East Queensland, Australia. Reg Environ Chang 14(2):527-539

Measham TG et al. (2011) Adapting to climate change through local municipal planning: barriers and challenges. Mitig Adapt Strat Gl Change 16(8):889-909

Moser S, Ekstrom J (2010) A framework to diagnose barriers to climate change adaptation. Proc Natl Acad Sci U S A 107(51):22026-22031

Munang R et al (2013) Climate change and ecosystem-based adaptation: a new pragmatic approach to buffering climate change impacts. Curr Opin Environ Sustain 5(1):67-71

Pahl-Wostl C (2009) A conceptual framework for analysing adaptive capacity and multi-level learning processes in resource governance regimes. Glob Environ Chang 19(3):354-365

Pasquini L, Cowling RM (2015) Opportunities and challenges for mainstreaming ecosystem-based adaptation in local government: evidence from the Western Cape, South Africa. Environ Dev Sustain 17(5):1121-1140

Pasquini L, Cowling RM, Ziervogel G (2013) Facing the heat: barriers to mainstreaming climate change adaptation in local government in the Western Cape Province, South Africa. Habitat Int 40:225-232

Pasquini L et al (2015) What enables local governments to mainstream climate change adaptation? Lessons learned from two municipal case studies in the Western Cape, South Africa. Climate Dev 7(1):60-70. doi: $10.1080 / 17565529.2014 .886994$

Pence GQK (2008) C.A.P.E. Fine-scale systematic conservation planning assessment: technical report, Cape Town, South Africa

Ribot J (2014) Cause and response: vulnerability and climate in the Anthropocene. J Peasant Stud 41(5):667-705

Roberts D et al (2012) Exploring ecosystem-based adaptation in Durban, South Africa: "learning-by-doing" at the local government coal face. Environ Urban 24(1):1-29

SACN (2012) Addressing the crisis of planning law reform in South Africa. Available at: http://sacitiesnetwork.co.za/

Sandström A, Bodin Ö, Crona B (2015) Network governance from the top - the case of ecosystem-based coastal and marine management. Mar Policy 55:57-63 Available at: http://www.sciencedirect. com/science/article/pii/S0308597X15000202

Shackleton S et al. (2015) Why is socially-just climate change adaptation in sub-Saharan Africa so challenging? A review of barriers identified from empirical cases. WIRES Clim Change 6(3):321-344

Stein BA et al (2013) Preparing for and managing change: climate adaptation for biodiversity and ecosystems. Front Ecol Environ 11(9):502-510

Termeer CJ (2009) Barriers to new modes of horizontal governance. Public Manage Rev 11(910895260):299-316

Uittenbroek C, Janssen-Jansen L, Runhaar H (2013) Mainstreaming climate adaptation into urban planning: overcoming barriers, seizing opportunities and evaluating the results in two Dutch case studies. Reg Environ Chang 13:399-411

Vignola R et al (2009) Ecosystem-based adaptation to climate change: what role for policy-makers, society and scientists? Mitig Adapt Strateg Glob Chang 14(8):691-696

Vignola R, McDaniels TL, Scholz RW (2013) Governance structures for ecosystem-based adaptation: using policy-network analysis to identify key organizations for bridging information across scales and policy areas. Environ Sci Policy 31:71-84

Wamsler C, Luederitz C, Brink E (2014) Local levers for change: mainstreaming ecosystem-based adaptation into municipal planning to foster sustainability transitions. Glob Environ Chang 29:189-201

Ziervogel G, Parnell S (2014) Tackling barriers to climate change adaptation in South African coastal cities. In: Glavovic BC, Smith GP (eds) Adapting to climate change. Springer, Dordrecht, pp 57-73

Ziervogel G, Archer Van Garderen E, Price P (2016) Strengthening the knowledge-policy interface through coproduction of an adaptation plan: leveraging opportunities in Bergrivier municipality, South Africa. Environ Urban 1-20 